\begin{tabular}{c} 
Jurnal Agriuma:, 1 (2) Oktober 2019 ISSN 2657-1749 (Print) ISSN 2657-1730 (Online) \\
DOI : 10.31289/agr.v1i2.3025 \\
JURNAL AGRIUMA \\
Available online http://ojs.uma.ac.id/index.php/agriuma \\
\hline
\end{tabular}

\title{
ANALISIS USAHATANI PEPAYA (Studi Kasus : Kecamatan Secanggang, Kabupaten Langkat, Sumatera Utara)
}

\author{
Bigner Dolok Saribu, Yusniar Lubis ${ }^{1}$,Mitra Musika Lubis ${ }^{2}$ \\ ${ }^{1}$ Agribisnis, Fakultas Pertanian, Universitas Medan Area, Indonesia \\ Diterima: Agustus 2019 Disetujui: Oktober 2019 Dipublish: Oktober 2019
}

*Coresponding Email: lubisyusniar@gmail.com

\section{Abstrak}

Tujuan penelitian ini adalah untuk mengetahui budidaya pepaya, untuk menganalisis biaya produksi dan penerimaan serta keuntungan petani papaya, dan untuk menganalisis kelayakan usahatani pepaya di Kecamatan Secanggang, Kabupaten Langkat. Penelitian di Kecamatan Secanggang, Kabupaten Langkat, Provinsi Sumatera Utara. Penentuan daerah penelitian dilakukan secara Pusposive (sengaja).Penelitian dilaksanakan pada bulan Mei - Juli 2017.Pengambilan sampel di lakukan metode sensus dengan mengambil 28 petani pepaya yang memiliki umur tanaman di atas 1 tahun. Hasil penelitian menunjukkan kondisi ketersediaan lahannya 0,5 ha sehingga jarak tanam tidak sesuai. Teknis budidaya belum ada peningkatan meskipun sudah 15 tahun berpengalaman.Hal ini dibuktikan dengan produktifitas lahan papaya hanya $19.260,51 \mathrm{~kg} /$ ha.Sementara produktivitas lahan pepaya yang baik 20 - 35 ton/ha.Rata-rata penerimaan petani sebesar Rp. 29.468.571 per petani atau Rp. 59.255.411 per hektar per tahun.Pendapatan usahataniyang diperoleh sebesar Rp. 22.333 .539 per petani atau Rp. 44.823.477 per hektar per tahun, dan setelah ditambah dengan nilai TKDK diperoleh pendapatan keluarga sebesar Rp. 23.889.254 per petani atau Rp. 48.500 .888 per hektar per tahun.Nilai RCR lebih besar dari 1 sehingga disimpulkan usahatani pepaya di daerah penelitian tergolong layak diusahai. Setiap pengeluaran biaya Rp. 1 akan menghasilkan penerimaan sebesar Rp. 4,13.

Kata Kunci : Analisis, Usahatani, Pepaya (,).

\begin{abstract}
The purpose of this study was to investigate papaya cultivation, to analyze the costs of production and acceptance and profits of papaya farmers, and to analyze the feasibility of papaya farming in Secanggang District, Langkat Regency. The sampling method was conducted by census by taking 28 papaya farmers who had plant life above 1 year. The results showed the condition of land availability was 0.5 ha so that the spacing was not suitable. The cultivation technique has not been improved even though it has been experienced for 15 years. This is evidenced by the productivity of papaya land at only 19,260.51 kg / ha. While papaya land productivity is good 20-35 tons / ha. The average farmer income is Rp. 29,468,571 per farmer or Rp. 59,255,411 per hectare per year. Farming income obtained is Rp. 22,333,539 per farmer or Rp. 44,823,477 per hectare per year, and after adding the TKDK value, the family income of Rp. 23,889,254 per farmer or Rp. 48,500,888 per hectare per year. RCR value is greater than 1 so it is concluded that papaya farming in the study area is classified as feasible. Every expenditure of Rp. 1 will generate revenue of Rp. 4.13.
\end{abstract}

Key Words: Analysis, Farming, Papaya (,)

How to Cite: Saribu, B.D. Lubis, Y., \& Lubis, M.M. 2019. ANALISIS USAHATANI PEPAYA.(Studi Kasus : Kecamatan Secanggang, Kabupaten Langkat, Sumatera Utara). Jurnal Agriuma. 1(2): 55-67. 


\section{PENDAHULUAN}

Buah buahan merupakan salah satu tanaman hortikultura yang bersifat musiman dan lebih dikenal sebagai sumber vitamin dan mineral, yang sangat penting peranannya dalam tubuh manusia karena berfungsi sebagai pengatur dan pelindung jaringan tubuh.Pembangunan perekonomian di Indonesia buah buahan mempunyai sumbangan yang tidak dapat di abaikan, karena banyak jenis buah buahan yang dapat tumbuh dan berbuah baik di Indonesia.

Kandungan gizi tertinggi yang terdapat dalam buah pepaya adalah vitamin A, yaitu 365 IU pada buah masak, 50 IU pada buah mentah, dan 18.250 IU pada daun. Hal ini dapat menunjukkan bahwa buah pepaya sangat penting dikonsumsi olehmanusia.

Produk Domestik Regional Bruto (PDRB) Provinsi Sumatera Utara Atas Dasar Harga Yang Berlaku (ADHB) pada tahun 2014 sebesar 523,77 triliun. Kategori Pertanian,Kehutanan, dan Perikanan kontributor utama dengan peranan mencapai 23,18 persen.Selanjutya diikuti oleh kategori industri pengolahan sebesar 19,90 persen dan kategori perdagangan besar dan eceran dan reparasi mobil dan sepeda motor sebesar 17,11 persen. Sementara itu, ketegori-kategori lainnya memberikan total kontribusi sebesar 39,81 persen terhadap perkonomian di Sumatera Utara.(BPS Sumatera Utara 2015). Peningkatan produksi buah pepaya juga cendrung meningkat. Hal ini dapat dilihat pada data BPS produksi buah pepaya tahun 2011 sampai dengan 2015 di Sumatera Utara pada tabel1.

Tabel 1. Produksi Buah Pepaya Tahun 2011-2015 di Sumatera Utara

\begin{tabular}{ll}
\hline Tahun & Produksi (ton) \\
\hline 2011 & 31,658 \\
2012 & 27,757 \\
2013 & 36,057 \\
2014 & 26,238 \\
2015 & 26,305 \\
\hline
\end{tabular}

Sumber: Data BPS Sumatera Utara, 2016

Tabel 1 dapat dilihat bahwa produksi buah pepaya cendrung mengalami peningkatan pada tahun 2011 sampai dengan 2013 walaupun terjadi penurunan pada tahun 2012 yaitu 
Bigner Dolok Saribu, Yusniar Lubis',Mitra Musika Lubis ${ }^{2}$, Analisis Usahatani Pepaya

dengan jumlah produksi sebesar 27,757 ton. Buah pepaya telah menjadi komoditi perdagangan Internasional saat ini dan menjadi produk ekspor beberapa negara produsen di kawasan Asia seperti Malaysia, Thailand, Philipina dan Indonesia.Pada kenyataannya buah pepaya belum menjadi produk ekspor unggulan Indonesia yang dapat diandalkan karena produksinya masih terbatas dan bahkan belum mencukupi kebutuhan dalam negeri.

Berdasarkan latar belakang yang ada maka perumusan masalah dalam penelitian ini adalah tentang bagaimana budidaya pepaya di Kecamatan Secanggang, Kabupaten Langkat, bagaimana biaya produksi dan penerimaan sertakeuntungan petani pepaya di Kecamatan Secanggang, Kabupaten Langkat dan bagaimana kelayakan usahatani pepaya di Kecamatan Secanggang, Kabupaten Langkat.Berdasarkan perumusan masalah, maka tujuan dari penelitian ini adalah untuk mengetahui budidaya pepaya di Kecamatan Secanggang, Kabupaten Langkat, untuk menganalisis biaya produksi dan penerimaan serta keuntungan petani pepaya di Kecamatan Secanggang, Kabupaten Langkat, dan untuk menganalisis kelayakan usahatani pepaya di Kecamatan Secanggang, Kabupaten Langkat.

\section{METODE PENELITIAN}

Penelitian ini dilaksanakan di Kecamatan Secanggang, Kabupaten Langkat, Provinsi Sumatera Utara.penentuan lokasi penelitian ini secara purposive (sengaja) dengan alasan penentuan lokasi penelitian karena di daerah ini merupakan salah satu daerah produksi pepaya di Kabupaten Langkat. Waktu penelitian akan dilakukan pada bulan Mei-Juli 2017. Teknik purposive merupakan teknik pengambilan sampel yang dilakukan dengan memilih satuan sampling atas dasar pertimbangan sekelompok pakar bidang ilmu yang sedang diteliti (Assaf AI 2009).Populasi penelitian ini adalah petani pepaya di Kecamatan Secanggang, Kabupaten Langkat, Provinsi Sumatera Utara.Jumlah petani pepaya yang terdapat di Kecamatan Secanggang, Kabupaten Langkat berjumlah 34 petani dan dengan jumlah 10.213 pohon.Jumlah data menjadi 28 orang ketika tahun 2016.Pengambilan sampel di lakukan metode sensus dengan mengambil 28 petani papaya dimana petani memiliki umur tanaman di atas 1 tahun yang terdapat di Kecamatan Secanggang, Kabupaten Langkat.Data yang dikumpulkan berupa data primer dan data dan analisis data yang digunakan dalam penelitian ini ialah analisis deskriptif tentang budidaya papaya, analisis biaya produksi dan analisis kelayakan usaha. 


\section{HASIL DAN PEMBAHASAN}

\section{Budidaya Usahatani Pepaya}

Tahap-tahap dalam budidaya usahatani pepaya adalah sebagai berikut:

1. Pemilihan benihpepaya

2. Penyemaian benihpepaya

3. Pengolahan tanah danpenanaman

4. Perawatan budidaya pepaya

5. Pemanenan

\section{Analisis Pendapatan dan Kelayakan Usahatani Pepaya Sarana Produksi}

Jenis sarana produksi yang digunakan pada usahatani pepaya di daerah penelitian terdiri dari pupuk Urea, SP-36, KCl dan ZA, serta pestisida Paratop dan Gramoxone. Ratarata jumlah sarana produksi yang digunakan petani selama satu tahun dapat dilihat pada Tabel2.

Tabel 2. Jumlah Penggunaan Sarana Produksi pada Usahatani Pepaya, Tahun 2016

\begin{tabular}{|c|c|c|c|}
\hline No & Jenis Saprodi & Per Petani & Per Hektar \\
\hline 1. & Kompos (kg) & $1.596,11$ & $3.210,37$ \\
\hline 2. & Urea (kg) & 91,36 & 182,92 \\
\hline 3. & SP-36 (kg) & 71,32 & 143,36 \\
\hline 4. & $\mathrm{KCl}(\mathrm{kg})$ & 61,89 & 124,81 \\
\hline 5. & $\mathrm{Za}(\mathrm{kg})$ & 43,00 & 85,96 \\
\hline 6. & Paratop (liter) & 3,14 & 6,49 \\
\hline 7. & $\begin{array}{l}\text { Gromoxon } \\
\text { (liter) }\end{array}$ & 3,75 & 7,50 \\
\hline
\end{tabular}

Sumber: Data Primer Diolah'

Dari Tabel 2 terlihat bahwa rata-rata penggunaan kompos di daerah penelitian adalah $1.596,11 \mathrm{~kg}$ per petani atau 3.210,37 kg per hektar. Jenis pupuk kimia yang paling banyak dignnakan adalah Urea, yaitu 91,36 kg per petani atau 182,92 kg per hektar, kemudian diikuti dengan SP-36sebanyak71,32kg per petani atau 143,36 kg per hektar dan KCl sebanyak 61,89 kg per petani atau 124,81 per hektar. Petani juga menggunakan pupuk ZA sebanyak 43,00 kg per petani atau 85,96 kg per hektar. Disamping itu, petani juga menggunakan pestisida jenis paratop sebanyak 3,14 liter per petani atau 6,49 liter per hektar dan 3,75 liter per petani atau 7,50 liter perhektar. 
Tabel 3. Nilai Penggunaan Sarana Produksi pada Usahatani Pepaya, Tahun 2016

\begin{tabular}{|c|c|c|c|}
\hline No & Jenis Saprodi & Per Petani & Per Hektar \\
\hline 1. & Kompos (Rp) & 2.394 .161 & 4.815 .561 \\
\hline 2. & Urea (Rp) & 200.986 & 402.430 \\
\hline 3. & SP-36 (Rp) & 499.250 & 1.003 .525 \\
\hline 4. & $\mathrm{KCl}(\mathrm{Rp})$ & 309.464 & 624.050 \\
\hline \multirow[t]{2}{*}{5.} & $\mathrm{Za}(\mathrm{Rp})$ & 94.600 & 189.114 \\
\hline & Total nilai pupuk (Rp) & 3.498 .461 & 7.034 .680 \\
\hline 6. & Paratop (Rp) & 188.571 & 389.507 \\
\hline 7. & Gromoxon (Rp) & 243.750 & 487.500 \\
\hline & Total nilai pestisida (Rp) & 432.321 & 877.007 \\
\hline & Total Saprodi (Rp) & 3.930 .782 & 7.911 .687 \\
\hline
\end{tabular}

Sumber: Data Primer Diolah

Tabel 3 menunjukkan bahwa nilai rata-rata penggunaan pupuk adalah sebesar Rp. 2.394.161 per petani atau Rp. 4.815.561 per hektar per tahun, sedangkan nilai pestisida yang digunakan adalah sebesar Rp. 432.321 per petani atau Rp. 877.007 per hektar per tahun.Secara keseluruhan, biaya yang dikeluarkan petani untuk sarana produksi adalah sebesar Rp. 3.930.782 per petani atau Rp. 7.911.687 per hektar per tahun.

\section{Tenaga Kerja}

Jenis kegiatan yang dilakukan petani setelah tanaman pepaya menghasilkan buah adalah pemupukan, penyemprotan, panen dan sortasi hasil panen.Tenaga kerja tersebut sebagian berasal dari dalam keluarga dan sebagian lagi berasal dari luar keluarga, terutama untuk usahatani yang relatif luas.Jumlah tenaga kerja yang digunakan pada masing-masing kegiatan dengan rata-rata pada Tabel 4. 
Tabel 4. Jumlah Pencurahan Tenaga Kerja pada Usahatani Pepaya, Tahun 2016

\begin{tabular}{lcrrr}
\hline No & KegiatanUsahatani & \multicolumn{2}{c}{$\begin{array}{c}\text { Per Petani } \\
\text { Per Hektar } \\
\text { (HKP) }\end{array}$} \\
\hline 1. & Pumber & 2,31 & 5,51 \\
& \multirow{2}{*}{ Pemupukan } & TKDK & 1,46 & 1,84 \\
& Penyemprotan & TKDK & 3,14 & 6,83 \\
& & TKLK & 1,07 & 1,35 \\
3. & Panen & TKDK & 13,11 & 31,58 \\
& & TKLK & 13,07 & 19,70 \\
\hline 4. & Sortasi & TKDK & 2,19 & 5,10 \\
& \multirow{2}{*}{ Total } & TKLK & 1,09 & 1,35 \\
& & TKDK & 20,74 & 49,03 \\
& & TKLK & 16,69 & 24,25 \\
\hline & & Jumlah & 37,44 & 73,28
\end{tabular}

Sumber: Data Primer Diolah

Dari Tabel 4 terlihat bahwa penggunaan tenaga kerja yang relatif besar adalah untuk panen. Rata-rata jumlah tenaga kerja untuk panen masing-masing adalah sebesar 13,11HKP per petani atau 31,58 per hektar TKDK per tahun dan 13,07 HKP per petani atau 19,70 HKP per hektar TKLK per tahun. Secara keseluruhan, total pencurahan tenaga kerja pada usahatani papaya adalah 37,44 HKP per petani atau 73,28 HKP per hektar pertahun.

Nilai tenaga kerja di daerah penelitian adalah sebesar Rp. 75.000 per HKP.Dengan demikian, total nilai tenaga kerja yang digunakan pada usahatani pepaya selama satu tahun dapat dihitung seperti tertera pada Lampiran 5, dengan rata-rata pada Tabel 5. 
Tabel 5. Nilai Pencurahan Tenaga Kerja pada Usahatani Pepaya, Tahun 2016

\begin{tabular}{lcrrr}
\hline No & Kegiatan & Sumber & Per Petani (Rp) & Per Hektar (Rp) \\
& Usahatani & & & \\
\hline 1. & Pemupukan & TKDK & 173.036 & 413.357 \\
& & TKLK & 109.821 & 138.107 \\
2. & Penyemprotan & TKDK & 235.714 & 512.598 \\
& & TKLK & 80.357 & 101.438 \\
3. & Panen & TKDK & 983.036 & 2.368 .634 \\
& & TKLK & 980.357 & 1.477 .393 \\
4. & Sortasi & TKDK & 163.929 & 382.821 \\
& & TKLK & 81.429 & 101.598 \\
\hline \multirow{3}{*}{ Total } & TKDK & 1.555 .714 & 3.677 .411 \\
& & TKLK & 1.251 .964 & 1.818 .536 \\
\hline & & Jumlah & 2.807 .679 & 5.495 .946 \\
\hline
\end{tabular}

Sumber: Data Primer Diolah

Tabel 5 menunjukkan bahwa nilai tenaga kerja selama satu tahun produksi pada usahatani pepaya adalah sebesar Rp. 2.807.679 per petani atau Rp. 5.495.946 per hektar per tahun. Nilai tenaga kerja yang bersumber dari dalam keluarga lebih besar, yaitu Rp. 1.555.714 per petani atau Rp. 3.677.411 per hektar TKDK, dibanding dengan nilai TKLK sebesar Rp. 1.251.964 per petani atau Rp. 1.818.536 perhektar.

\section{Penyusutan Peralatan}

Peralatan yang digunakan petani pepaya adalah cangkul, beko, parang, knapsacksprayer, ember dan babat.Jumlah dan nilai penyusutan masing-masing peralatan selama satu tahun dapat dilihat pada Tabel 6. 
Bigner Dolok Saribu, Yusniar Lubis1,Mitra Musika Lubis ${ }^{2}$, Analisis Usahatani Pepaya

Tabel 6. Nilai Penyusutan Peralatan pada Usahatani Pepaya, Tahun 2016

\begin{tabular}{ccrr}
\hline No & Jenis Peralatan & Per Petani (Rp) & Per Hektar (Rp) \\
\hline 1. & Cangkul & 43.750 & 105.920 \\
2. & Beko & 125.000 & 303.825 \\
3. & Parang & 25.893 & 82.884 \\
4. & Knapsacksprayer & 70.000 & 211.225 \\
5. & Ember & 30.536 & 95.009 \\
6. & Babat & 25.000 & 75.438 \\
\hline & Total & 320.179 & 874.300 \\
\hline
\end{tabular}

Sumber: Data Primer Diolah

Dari Tabel 6 terlihat bahwa penyusutan terbesar bersumber dari peralatan beko dan knapsacksprayer, dengan nilai sebesar Rp. 125.000 per petani atau Rp. 303.825 per hektar untuk beko, serta Rp. 70.000 per petani atau Rp. 211.225 per hektar untuk Knapsacksprayer selama satu tahun. Sedangkan nilai penyusutan peralatan lainnya relatif lebih kecil.Secara keseluruhan, nilai penyusutan peralatan adalah sebesar Rp. 320.179 per petani atau Rp. 874.300 per hektar per tahun.

\section{Total Biaya Pemeliharaan}

Total biaya pemeliharaan merupakan penjumlahan dari biaya sarana produksi, nilai tenaga kerja, dan penyusutan peralatan. Total biaya pemeliharaan pepaya selama satu tahun produksi dapat dilihat pada Tabel 7.

Tabel 7. Total Biaya Pemeliharaan pada Usahatani Pepaya, Tahun 2016

\begin{tabular}{lcrr}
\hline No & Jenis Biaya & Per Petani (Rp) & \multicolumn{1}{c}{ Per Hektar (Rp) } \\
\hline 1. & Sarana produksi & 3.930 .782 & 7.911 .687 \\
2. & Tenaga kerja & 2.807 .679 & 5.495 .946 \\
3. & Penyusutan peralatan & 320.179 & 874.300 \\
4. & PBB & 76.393 & 150.000 \\
\hline & Total Biaya & 7.135 .032 & 14.431 .933 \\
\hline
\end{tabular}

Sumber: Data Primer Diolah 
Dari Tabel 7 terlihat bahwa jenis pemeliharaan yang relatif besar adalah biaya sarana produksi dan tenaga kerja.Biaya sarana produksi mencapai $\mathrm{Rp} .3 .930 .782$ per petani atau Rp. 7.911.687 per hektar, sedangkan biaya tenaga kerja mencapai Rp. 2.807.679 per petani atau Rp. 5.495.946 per hektar per tahun. Secara keseluruhan, total biaya produksi usahatani papaya di daerah penelitian adalah Rp. 7.135 .032 per petani atau Rp. 14.431 .933 per hektar per tahun.

Biaya produksi yang dikeluarkan petani di daerah penelitian adalah sebesar Rp. 14.431.933 per hektar, lebih kecil dari biaya produksi penelitian terdahulu Rina Chaerningrum (2010) dimana luas lahan 0,5 ha mengeluarkan biaya produksi $\mathrm{Rp}$. 71.859.000 per hektar. Perbedaan biaya produksi relatif sangat jauh disebabkan dari segi perawatan yang dilakukan oleh peneliti terdahulu sudah tergolong modern, sedangkan penelitian ini masih cara tradisional.

\section{Produksi dan Produktivitas}

Produksi pepaya diukur dalam satuan kilogram yang dihasilkan dari lahan seluas yang diusahai masing-masing petani.Sedangkan produktivitas adalah produksi per hekar, yang dihitung dengan membagikan jumlah produksi terhadap luas lahan.Hasil produksi dan produktivitas usahatani pepaya selama satu tahun produksi dapat dilihat pada Tabel 8.

Tabel 8. Produksi dan Produktivitas pada Usahatani Pepaya, Tahun 2016

\begin{tabular}{ccr}
\hline No & Uraian & Nilai \\
\hline 1. & Luas Lahan (ha) & 0,51 \\
2. & Produksi (kg) & $9.822,86$ \\
3. & Produktivitas & $19.260,51$ \\
& (kg/ha) & \\
\hline
\end{tabular}

Sumber: Data Primer Diolah 
Dari Tabel 8 terlihat bahwa rata-rata luas lahan yang diusahai dengan seluas 0,51 ha, diperoleh jumlah produksi rata-rata sebesar 9.822,86 kg per tahun. Sedangkan produktivitas yang dihasilkan adalah sebesar 19.260,51 kg per hektar per tahun.

\section{Penerimaan dan Pendapatan serta Kelayakan Usahatani}

Penerimaan adalah nilai produksi pepaya yang dihasilkan, dihitung dengan mengalikan jumlah produksi terhadap harga jual pada tingkat petani, yaitu sebesar Rp. 3.000 per kg buah pepaya. Sedangkan pendapatan adalah nilai penerimaan dikurangi dengan total biaya pemeliharaan. Hasil perhitungan selengkapnya dapat dilihat pada Tabel9.

Tabel 9. Penerimaan dan Pendapatan pada Usahatani Pepaya, Tahun 2016

\begin{tabular}{ccrr}
\hline No & Jenis Biaya & \multicolumn{1}{c}{ Per Petani } & \multicolumn{1}{c}{ Per Hektar } \\
\hline 1. & Penerimaan (Rp) & 29.468 .571 & 59.255 .411 \\
2. & Biaya Produksi (Rp) & 7.135 .032 & 14.431 .933 \\
3. & Pendapatan Bersih (Rp) & 22.333 .539 & 44.823 .477 \\
4. & RCR (Rp) & 4,13 & 4,13 \\
\hline
\end{tabular}

Sumber: Data Primer Diolah

Dari Tabel 9 terlihat bahwa, nilai rata-rata penerimaan petani adalah sebesar Rp. 29.468.571 per petani atau Rp. 59.255.411 per hektar per tahun.Setelah dikurangi biaya pemeliharaan, maka pendapatan usahatani yang diperoleh adalah sebesar Rp. 22.333.539 per petani atau Rp. 44.823.477 per hektar per tahun.

Kelayakan usahatani papaya di daerah penelitian dapat dilihat dari nilai RCR, yaitu sebesar 4,13. Nilai RCR tersebut lebih besar dari 1 sehingga disimpulkan bahwa usahatani papaya di daerah penelitian tergolong layak diusahai. Setiap pengeluaran biaya Rp. 1 akan menghasilkan penerimaan sebesar Rp. 4,13.

Dari segi kelayakan usahatani maka hasil penelitian masih belum berhasil dibanding penelitian terdahulu oleh Herry Nur Faisal (2013) dimana nilai R/C mencapai 6,30. Walaupun nilai R/C usahatani di Kecamatan Secanggang tergolong rendah $(4,13)$ 
Bigner Dolok Saribu, Yusniar Lubis1,Mitra Musika Lubis ${ }^{2}$, Analisis Usahatani Pepaya

dibanding pada daerah-daearah lain tetapi masih layak untuk diusahakan.

Investasi Usahatani Pepaya

Invenstasi usahatani papaya dilakukan dengan menghitung biaya usaha tanaman sebelum menghasilkan dan sesudah menghasilkan. Budidaya pepaya di daerah penelitian selama 3 tahun, dimana selama tahun pertama belum menghasilkan, dan setelah berumur 9 - 14 bulan tanaman sudah berproduksi, sehingga produksi usahatani dihitung mulai tahun kedua dan ketiga. Berikut biaya yang dikeluarkan petani sebelum tanaman pepaya menghasilkan sampai tanaman tidak menghasilkan lagi sehingga perlu dilakukan

replanting.

Tabel 14. Kebutuhan Investasi Usahatani Pepaya

\begin{tabular}{|c|c|c|c|c|c|}
\hline No & Uraian & Tahun I & Tahun II & Tahun III & Total \\
\hline \multirow[t]{13}{*}{$\mathbf{1}$} & Sarana Produksi & & & & \\
\hline & Bibit & - & - & - & - \\
\hline & Pupuk: & & & & \\
\hline & a. Kompos & $3,611,671$ & $4,815,561$ & $4,815,561$ & $13,242,793$ \\
\hline & b. Urea & 301,822 & 402,430 & 402,430 & $1,106,681$ \\
\hline & c. SP-36 & 752,644 & $1,003,525$ & $1,003,525$ & $2,759,694$ \\
\hline & d. KCl & 468,038 & 624,050 & 624,050 & $1,716,138$ \\
\hline & e. ZA & 141,836 & 189,114 & 189,114 & 520,065 \\
\hline & Total Pupuk & $5,276,011$ & $7,034,680$ & $7,034,680$ & $19,345,371$ \\
\hline & Pestisida: & & & & \\
\hline & a. Paratop & 292,130 & 389,507 & 389,507 & $1,071,144$ \\
\hline & b. Gromoxon & 365,625 & 487,500 & 487,500 & $1,340,625$ \\
\hline & Total Pestisida & 657,755 & 877,007 & 877,007 & $2,411,769$ \\
\hline \multirow[t]{7}{*}{2} & Tenaga Kerja & & & & \\
\hline & a. Penanaman & 500,000 & - & - & 500,000 \\
\hline & b. Pemupukan & 413,598 & 551,464 & 551,464 & $1,516,527$ \\
\hline & c. Penyemprotan & 460,527 & 614,036 & 614,036 & $1,688,598$ \\
\hline & d. Panen & $2,884,520$ & $3,846,027$ & $3,846,027$ & $10,576,574$ \\
\hline & e. Sortasi & 363,315 & 484,420 & 484,420 & $1,332,154$ \\
\hline & Total Tenaga Kerja & $4,621,960$ & $5,495,946$ & $5,495,946$ & $15,613,853$ \\
\hline \multirow[t]{8}{*}{3} & Penyusutan Peralatan & & & & \\
\hline & a. Cangkul & 105,920 & 105,920 & 105,920 & 317,759 \\
\hline & b. Beko & 303,825 & 303,825 & 303,825 & 911,475 \\
\hline & c. Parang & 82,884 & 82,884 & 82,884 & 248,652 \\
\hline & d. Knapsacksprayer & 211,225 & 211,225 & 211,225 & 633,675 \\
\hline & e. Ember & 95,009 & 95,009 & 95,009 & 285,027 \\
\hline & f. Babat & 75,438 & 75,438 & 75,438 & 226,313 \\
\hline & Total Penyusutan & 874,300 & 874,300 & 874,300 & $2,622,900$ \\
\hline 4 & PBB & 150,000 & 150,000 & 150,000 & 450,000 \\
\hline 5 & Total Investasi & $11,580,026$ & $14,431,933$ & $14,431,933$ & $40,443,893$ \\
\hline
\end{tabular}

Sumber: Data Primer Diolah 
Usahatani pepaya memiliki biaya investasi sebagai berikut:

Tahun I : Rp.11.580.026

Tahun II : Rp. 14.431 .933

Tahun III : Rp. 14.431 .933

Total : Rp.40.443.893

Dengan demikian biaya investasi per hektar adalah Rp. 40.443.893. Menurut informasi petani perkembangan harga pepaya setiap tahun hanya mengalami perubahan yang sedikit, yaitu Rp. 2.750 pada tahun 2015 dan Rp. 3.000 pada tahun 2016.

\section{SIMPULAN}

Dari hasil penelitian dapat dibuat beberapa kesimpulan sebagai berikut: Kondisi ketersediaan lahannya 0,5 ha sehingga jarak tanam tidak sesuai. Teknis budidaya belum ada peningkatan meskipun sudah 15 tahun berpengalaman.Hal ini dibuktikan dengan produktifitas lahan papaya hanya 19.260,51 ton/ha.Sementara produktivitas lahan pepaya yang baik 20 - 35 ton/ha.Rata-rata penerimaan petani adalah sebesar Rp. 29.468.571 per petani atau Rp. 59.255.411 per hektar per tahun.Setelah dikurangi biaya pemeliharaan, maka pendapatanusahataniyangdiperolehadalahsebesarRp.22.333.539perpetaniatauRp.

44.823.477 per hektar per tahun, dan setelah ditambah dengan nilai TKDK diperoleh pendapatan keluarga sebesar Rp. 23.889.254 per petani atau Rp. 48.500.888 per hektar per tahun.Nilai RCR tersebut lebih besar dari 1 sehingga disimpulkan bahwa usahatani papaya di daerah penelitian tergolong layak diusahai. Setiap pengeluaran biaya Rp. 1 akan menghasilkan penerimaan sebesar Rp.4,13. 
Bigner Dolok Saribu, Yusniar Lubis,Mitra Musika Lubis² , Analisis Usahatani Pepaya

\section{DAFTAR PUSTAKA}

Ai, Assaf, 2009. Penelitian Bisnis Kuantitatif. PT Grasindo. Jakarta.

Badan Pusat Statistik (BPS). 2016. Sumatera Utara dalam angka 2016. Provinsi Sumatera Utara. Medan

Chaerningrum, Rina, 2010. Analisis Usahatani Pepaya. Skirpsi.Program Studi Depertement Agribisnis Fakultas Ekonomi Manajemen IPB Bogor.Diakses 24 Januari 2010.

Departemen Pertanian 2014 Sumatera Utara Dalam Angka 2014. Badan Pusat Statistik Provinsi Sumatera Utara. Medan

Ditjen Hortikultura Direktorat Jenderal Hortikultura. 2005. Vademekum Pepaya (Carica Papaya). Sumatera Utara: Direktorat Jenderal.

Direktorat Gizi. Depkes RI. 2012. Komposisi Buah dan Daun Pepaya. Jakarta.

Faisal, Herry, Nur. 2013. Analisis Pendapatan Usahatani dan Saluran Pemasaran Pepaya (Carica papaya L).Jurnal. Agribisnis Fakultas Pertanian Unita Vol. 11 No. 13 April 2015. Tulungagung.

Khairiyakh, Refa'ul, 2011. Analisis Usahatani Pepaya. Jurnal.VOL 10 No. 1. 2014. HAL 14- 22.Program Study Agribisnis Fakultas Pertanian Jambi

Limbong, WH. dan P. Sitorus. 1997. Pengantar Tataniaga Pertanian. Jurusan Ilmu-ilmu Sosial Ekonomi Pertanian, Fakultas Pertanian, Institut Pertanian Bogor. Bogor.

Purba, Andry Pandapotan, 2008. Analisis Pendapatan Usahatani dan Saluran Pemasaran Pepaya California.Skirpsi.Program Studi Agribisnis Fakultas Pertanian IPB Bogor.Diakses 21 Desember 2014.

Ramadhian, Ivan Nur,2012.Pengaruh Budidaya Pepaya California Terhadap Kondisi Sosial Ekonomi Pertanian.Skirpsi. Program Study Agribisnis Fakultas Pertanian Universitas Pendidikan Indonesia, Diakses 11 Februari 2014.Jawa Barat

Susanti, Tuti dkk.2013. Analisis Pemasaran dan Pendapatan Usahatani Pepaya Mini (Carica papaya L).Jurnal.AGRIFOR Volume XIII Nomor 1, Maret 2014.Kalimantan Timur. Balikpapan. 